\author{
Masaki Kawase MD, * \\ Toru Komatsu MD, $\dagger$ \\ Kimitoshi Nishiwaki MD,‡ \\ Tomomasa Kimura MD, * \\ Yoshihiro Fujiwara MD,* \\ Toshimichi Takahashi $\mathrm{MD}, *$ \\ Yasuhiro Shimada $\mathrm{MD}^{*}$
}

\section{Heart rate variability during massive hemor- rhage and progressive hemorrhagic shock in dogs}

Purpose: To investigate the sequential changes in heart rate (HR), autonomic nervous activity presented by the spectral analysis of heart rate variability (HRV), hemodynamics and metabolism during massive hemorrhage and progressive hemorrhagic shock in dogs.

Methods: Twelve dogs were subjected to acute massive hemorrhage until mean arterial pressure (MAP) reached $50 \mathrm{mmHg}$. Then bleeding was stopped and they were allowed to reach a plateau phase. They were divided, post hoc, into bradycardic or tachycardic groups according to their HR response to the acute massive hemorrhage. After reaching a plateau phase, the dogs were further bled to keep their MAP around $50 \mathrm{mmHg}$ (progressive hemorrhagic shock). Their heart rate power spectra were quantified into low-frequency (LF) $(0.04-0.15 \mathrm{~Hz})$ and high-frequency (HF) (0.15-0.4 Hz) components.

Results: In the bradycardic group, both LF and HF increased after massive hemorrhage, but during progressive hemorrhagic shock these components decreased while HR increased. In the tachycardic group, LF increased after massive hemorrhage, but during progressive hemorrhagic shock LF decreased with continuous suppression of HF.

Conclusion: Massive hemorrhage caused two types of HR response: bradycardia and tachycardia. The HRV profile showed differential autonomic characteristics, and could be a valuable tool in assessing various degrees of hemorrhagic shock.

Objectif: Examiner les changements de fréquence cardiaque (FC), l'activité nerveuse autonome selon l'analyse spectrale de la variabilité de la fréquence cardiaque (VFC), l'hémodynamie et le métabolisme pendant une hémorragie massive et un choc hémorragique progressif, chez des chiens.

Méthode : Douze chiens ont été soumis à une hémorragie aiguë massive jusqu'à ce que la tension artérielle moyenne (TAM) atteigne $50 \mathrm{mmHg}$. Puis, on a arrêté le saignement et laissé la pression parvenir à un plateau. On a, en conséquence, réparti les animaux en groupe bradycardie ou tachycardie selon le comportement de la FC pendant l'hémorragie aiguë massive. Un plateau une fois atteint, les chiens ont subi une autre hémorragie pour amener leur TAM autour de $50 \mathrm{mmHg}$ (choc hémorragique progressif). Le spectre de la puissance de la fréquence cardiaque a été quantifié en composantes de basses fréquences $(\mathrm{BF})(0,04-0,15 \mathrm{~Hz})$ et de hautes fréquences $(\mathrm{HF})(0,15-0,4 \mathrm{~Hz})$.

Résultats : Dans le groupe bradycardie, les BF et HF ont augmenté après l'hémorragie massive, mais lors du choc hémorragique progressif, ces composantes ont diminué pendant que la FC augmentait. Dans le groupe tachycardie, les BF ont augmenté après l'hémorragie massive, mais lors du choc, elles ont baissé en même temps que survenait la suppression continue des HF.

Conclusion : L'hémorragie massive a causé deux types de réaction de la FC : la bradycardie et la tachycardie. Le profil de VFC a affiché des caractéristiques autonomes différentielles, ce qui en fait un outil valable pour évaluer différents degrés de choc hémorragique.

From the Department of Anesthesiology, Nagoya University School of Medicine, ${ }^{*}$ the Department of Anesthesiology and Acute Medicine, Aichi Medical University, $†$ and the Department of Anesthesiology, the first Nagoya Red Cross Hospital, $\ddagger$ Japan.

Address correspondence to: Masaki Kawase MD, Department of Anesthesiology, Nagoya University School of Medicine, 65 Tsurumai-

cho, Showa-ku, Nagoya 466-8550, Japan. Phone: +81-52-744-2340; Fax: +81-52-744-2342; E-mail: FZA00627@niftyserve.or.jp

This study was performed at the Department of Anesthesiology, Nagoya University School of Medicine, Nagoya, Japan.

Accepted for publication April 30, 2000.

CAN J ANESTH 2000/47: 8/pp 807-814 
$\mathrm{T}$

ACHYCARDIAis considered to be characteristic of acute hemorrhage, but during massive hemorrhage (defined as the loss of approximately $30 \%$ of estimated blood volume), reversible bradycardia responsive to volume resuscitation follows. ${ }^{1-6}$ Reversible bradycardia is a decrease of heart rate (HR), total peripheral resistance and blood pressure due to activation of unmyelinated vagal afferents (C-fibres) from the left ventricle. ${ }^{6}$ Experimental blockade of the cardiac vagus nerve abolishes this response. ${ }^{7,8}$ When the hemorrhage has progressed further, sympathetic excitation followed by inhibition and vasomotor paralysis occurs at the irreversible stage of hemorrhagic shock. ${ }^{9-12}$

Secher et al. recently separated HR responses to reduced blood volume into three stages: normotension with moderate tachycardia, moderate hypotension with bradycardia, and severe hypotension with tachycardia. ${ }^{6}$ The neural regulation of circulatory function is mainly affected by the interplay of sympathetic and parasympathetic outflows, and activation of either of these is accompanied by inhibition of the other. ${ }^{13}$ However, little is known about the relationship between HR response and autonomic balance with respect to $\mathrm{HR}$ changes during graded hemorrhage.

Heart rate variability (HRV) provides some information about the autonomic control of the cardiovascular system. ${ }^{14-18}$ One of the methods for evaluating HRV is spectral analysis. We have previously shown that anesthesia and hemorrhage cause changes in HRV. ${ }^{19,20}$ Only a few studies, however, have focused on the changes in HRV during hemorrhage, ${ }^{21,22}$ and little is known about the sequential changes in HRV during massive progressive hemorrhage under anesthesia with mechanical ventilation.

The purpose of this study was to investigate how massive progressive hemorrhage affected the pattern of HRV concomitant with hemodynamic and metabolic changes in anesthetized, mechanically-ventilated dogs.

Materials and methods

The institutional review board of the Animal Investigation Committee of our School approved all experimental procedures and the protocols for this study. Twelve dogs weighing an average of $16.4 \mathrm{~kg}$ were anesthetized with $10 \mathrm{mg} \cdot \mathrm{kg}^{-1}$ thiamylal $i v$ and the tracheas were intubated after $2 \mathrm{mg} \cdot \mathrm{kg}^{-1}$ succinylcholine iv. Anesthesia was maintained with alphachloralose $\left(50 \mathrm{mg} \cdot \mathrm{kg}^{-1}\right.$ bolus and $15 \mathrm{mg} \cdot \mathrm{kg}^{-1} \cdot \mathrm{hr}^{-1}$ $i v)^{23}$ and vecuronium $\left(0.1 \mathrm{mg} \cdot \mathrm{kg}^{-1}\right.$ bolus and 0.1 $\left.\mathrm{mg} \cdot \mathrm{kg}^{-1} \cdot \mathrm{hr}^{-1} i v\right)$, and the lungs were mechanically ventilated with room air at 14 breaths $\min ^{-1}$. Catheters were placed in the abdominal aorta to measure arterial blood pressure and in the left femoral artery to draw blood. A venous cannula was inserted in the upper extremity and was used to infuse drugs. Splenectomy was performed to avoid the blood reservoir effect. ${ }^{24}$ Throughout the experiment, body temperature was kept within the normal range.

When the animals' conditions had stabilized (control phase), they were bled rapidly through the arterial catheter until mean arterial blood pressure (MAP) reached $50 \mathrm{mmHg}$. At this point, we stopped removing blood and observed that MAP recovered and plateaued. When the plateaued blood pressure was maintained for at least $10 \mathrm{~min}$, we then started withdrawing blood again. The MAP was maintained at around $50 \mathrm{mmHg}$ by further withdrawing blood (progressive hemorrhage). Our four experimental phases were defined as follows: control phase, first acute phase (the acute bleeding phase immediately after the control phase), first plateau phase after acute bleeding, and final plateau phase (when the MAP was maintained at around 50 $\mathrm{mmHg}$ in the presence of progressive hemorrhage).

The analysis of HRV was performed as follows. Online analysis of RR intervals was performed by detecting an $\mathrm{R}$ wave from the signal of the electrocardiogram, using a microcomputer and the data were stored on a magnetic optical disk. Off-line spectral analysis was performed on 608-sec segments of RR intervals of each phase. Consequently, an instantaneous HR time series was constructed as $1 / R R$ interval length and sampled at $4 \mathrm{~Hz}$. Then, power spectra were computed using the fast Fourier transformation program. The power spectra were normalized by squared mean heart rate. The heart rate power spectra were quantified by determining the areas of the spectrum in two component widths: low-frequency component (LF) $(0.04-0.15 \mathrm{~Hz})$ and high-frequency component $(\mathrm{HF})(0.15-0.4 \mathrm{~Hz})$. The LF mainly reflects both sympathetic nervous activity and parasympathetic nervous activity, and the HF mainly reflects parasympathetic nervous activity. ${ }^{15,16}$ To estimate the autonomic balance, $\mathrm{LF} / \mathrm{HF}$ ratio and normalized unit powers were calculated as a marker of sympatho-parasympathetic balance. The LF/HF ratio indicates any predominant shift in the sympathoparasympathetic balance; changes towards a higher or lower ratio mean more sympathetic or more parasympathetic predominance, respectively. ${ }^{16-18}$ The normalized unit power of the spectral peaks within each measurement was calculated as follows: nuLF; $\mathrm{LF} /(\mathrm{LF}+\mathrm{HF}) \times 100(\%)$, and nuHF; $\mathrm{HF} /(\mathrm{LF}+\mathrm{HF}) \times$ $100(\%)$. NuLF and nuHF were taken as markers of sympathetic and parasympathetic nervous activity, respectively. ${ }^{14,17,19}$ 
Spectral analysis needs steady state data. However, it is difficult to obtain a steady period of more than $608 \mathrm{sec}$. We solved this problem by deriving 608 -sec segment LF and HF measurements using sequential analysis of overlapping 128 -sec data segments, with each sequential 128-sec segment beginning $32 \mathrm{sec}$ after the beginning of the previous segment. ${ }^{19} \mathrm{Six}$ hundred and eight-sec LF and HF segments were summed into 16 sequential trended sub-segments of power spectral arrays, which are shown on a threedimensional surface in Figure 1. We obtained LF and HF values by averaging the 16 sequential trended measurements.

Figure 1 shows typical examples of MAP and HR changes during the experiment. After the massive hemorrhage, HR and MAP showed two types of changes, so we divided the 12 dogs into two groups post hoc. The bradycardic group $(n=8)$ showed a transient tachycardia followed by bradycardia in which the lowest HR was less than the control HR immediately

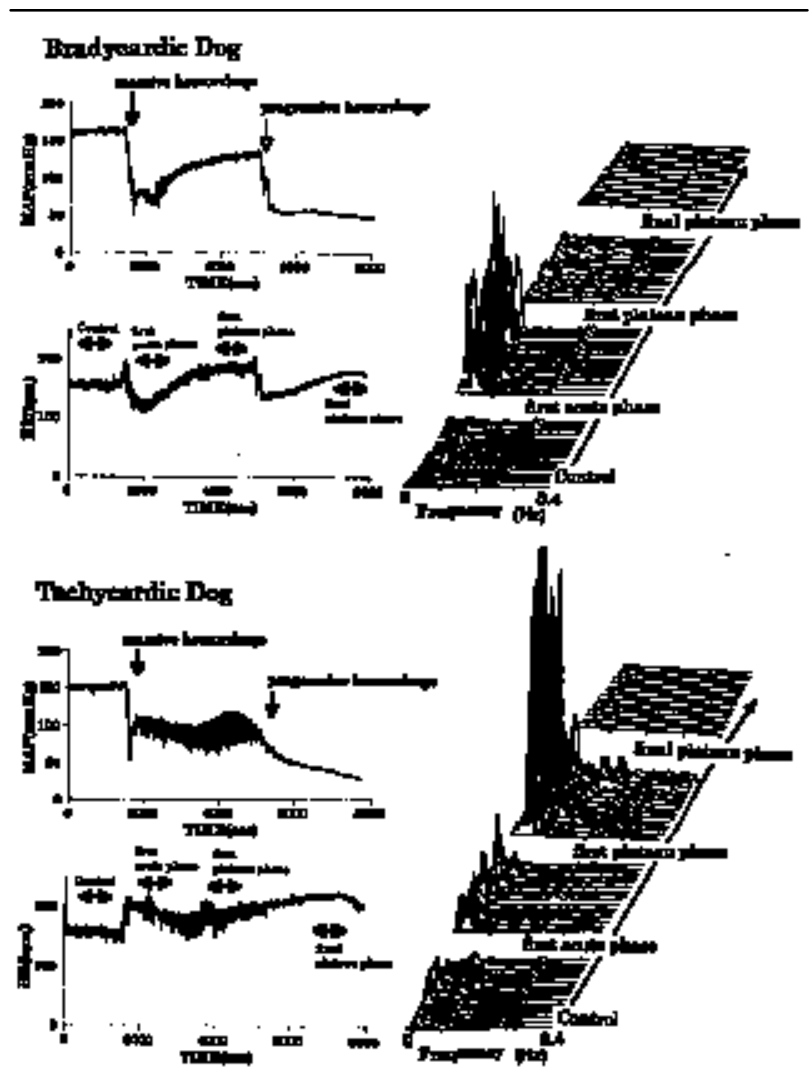

FIGURE 1 Typical diagrams of sequential changes mean arterial blood pressure (MAP), heart rate (HR), and heart rate variability (HRV) in a dog in the bradycardic group (upper panel), and in a dog in the tachycardic group (lower panel) during massive hemorrhage and progressive hemorrhagic shock. after massive hemorrhage and the HR increased more than the control value in about $30 \mathrm{~min}$, while the MAP showed a plateau phase. The tachycardic group $(n=4)$ showed continuous tachycardia more than the control HR immediately after massive hemorrhage. The amount of hemorrhage in both groups was comparable ( bradycardic group, $304 \pm 96 \mathrm{~mL}$; tachycardic group, $253 \pm 150 \mathrm{~mL} ; P$ : NS). However, during progressive hemorrhage, HR and MAP showed almost the same pattern in both groups. One dog in the tachycardic group died before the final plateau phase. The amount of additional hemorrhage after the first plateau phase in both groups was comparable (bradycardic group, $129 \pm 52 \mathrm{~mL}$, tachycardic group, $105 \pm$ $148 \mathrm{~mL} ; P: \mathrm{NS}$ ).

To compare the effects of hemorrhagic shock, we investigated hemodynamic and metabolic variables in each phase. Hemodynamic variables included mean pulmonary arterial pressure (PA), pulmonary capillary wedge pressure (PCWP), central venous pressure (CVP), mixed venous oxygen saturation $\left(\mathrm{S}_{\overline{\mathrm{v}}} \mathrm{O}_{2}\right)$ and cardiac output $(\mathrm{CO})$ by a flow-directed pulmonary artery catheter (Baxter). The metabolic variables included $\mathrm{Hb}, \mathrm{pH}, \mathrm{HCO}_{3}^{-}, \mathrm{BE}$ and lactate, measured by arterial blood analysis.

To confirm a normal distribution, LF and HF were calculated by taking the common logarithm of the power spectra of each component. ${ }^{19,20}$ Data are expressed as mean \pm SD. Comparisons for the timecourse within a group were analyzed by using one-way repeated measurement of analysis of variance followed by multiple comparisons of Fisher PLSD to assess LF, $\mathrm{HF}$ and the numeral data except LF/HF ratio, nuLF and nuHF. Comparisons between groups were analyzed by analysis of variance followed by multiple comparisons of Fisher PLSD. With respect to the LF/HF ratio, nuLF and nuHF, the non-parametric Friedman test, followed by multiple comparisons of the Student-Newman-Keuls test, were used to assess comparisons of the LF/HF ratio, nuLF and nuHF for the time-course within a group. In addition, the Mann-Whitney $\mathrm{U}$ test was used to assess comparisons between the groups. $P<0.05$ was considered statistically significant.

Results

Changes in MAP and HR (Figure 2).

In the first acute phase, MAP in both groups decreased compared with the control value, but they increased above $50 \mathrm{mmHg}$. In the first plateau phase, MAP in the bradycardic group increased compared with the first acute value. During the final plateau phase, MAP in both groups decreased .The difference 

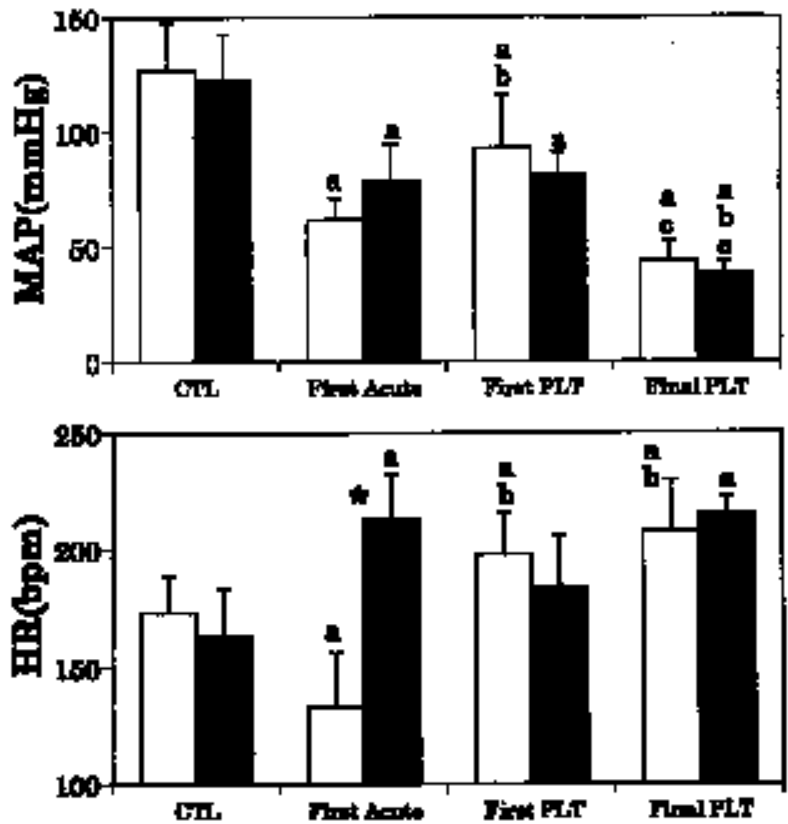

FIGURE 2 Changes in mean arterial pressure (MAP) and heart rate (HR) during massive hemorrhage and progressive hemorrhagic shock. In the first acute phase, the lowest HR values were compared between the groups. HR in other phases and MAP were calculated by averaging each value obtained 608 -sec from the start of each phase.

a: $P<0.05$ vs CTL; b: $P<0.05$ vs First Acute; c: $P<0.05$ vs First PLT; ${ }^{*}: P<0.05$ vs tachycardic group. Open bars: bradycardic group; solid bars: tachycardic group. CTL: control phase; First Acute: first acute phase; First PLT: first plateau phase; Final PLT: final plateau phase.

in MAP between both groups was not significant in any phase.

In the first acute phase, HR in the bradycardic group decreased compared with the control value, while HR in the tachycardic group increased compared with the control value, and the difference between the groups reached statistical significance. In the first and final plateau phases, HR in the bradycardic group increased compared with the control and first acute values. In the final plateau phase, HR in the tachycardic group showed an increase compared with the control value.

\section{Changes in HRV (Figures 3, 4)}

In the first acute phase, LF in the bradycardic group increased compared with the control value, while in the first plateau phase, LF in the tachycardic group increased compared with the control value. On the
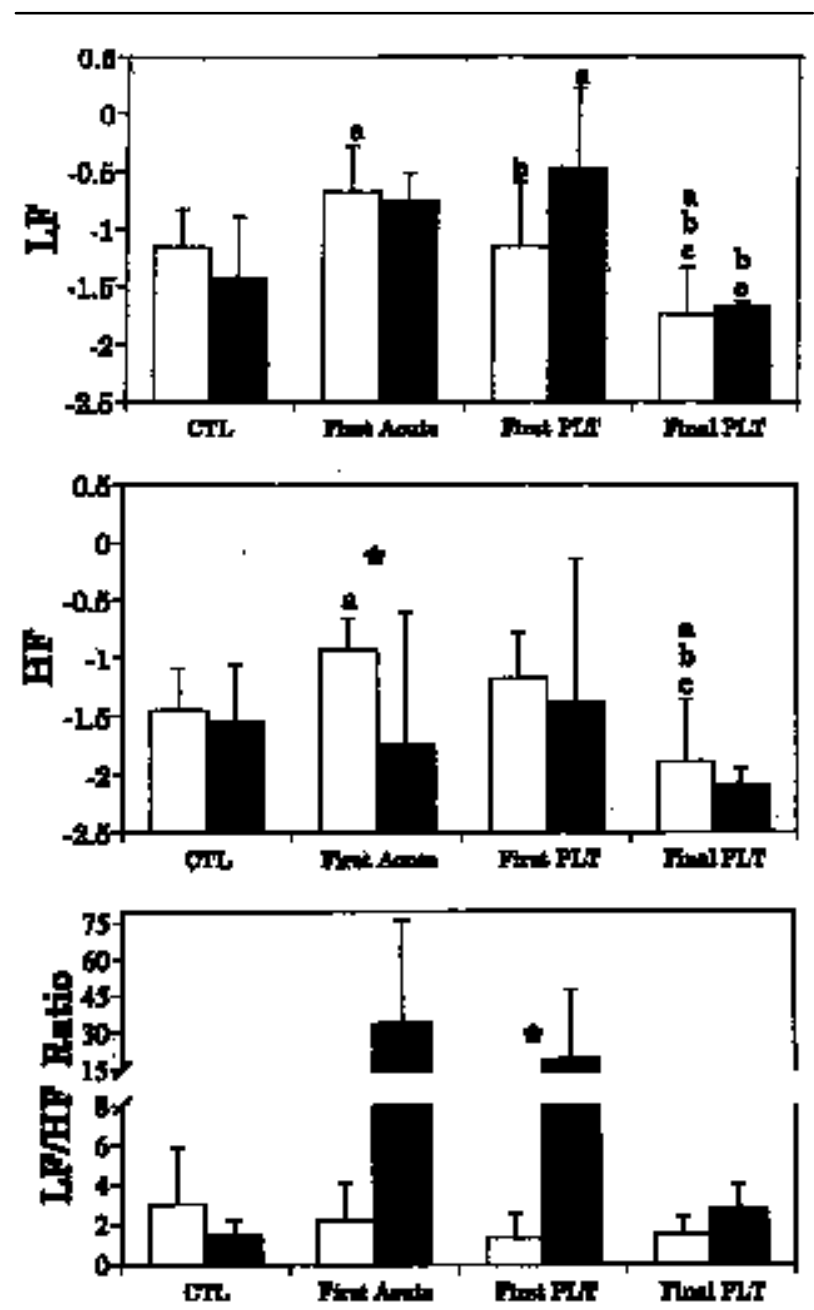

FIGURE 3 Changes in heart rate variability values during massive hemorrhage and progressive hemorrhagic shock. a: $P<0.05$ vs CTL; b: $P<0.05$ vs First Acute; c: $P<0.05$ vs First PLT; * $P<0.05$ vs tachycardic group. Open bars: bradycardic group; solid bars: tachycardic group. LF: low-frequency component; HF: high frequency component; LF/HF ratio: low-frequency to high-frequency ratio; nuLF: normalized LF unit power; nuHF: normalized HF unit power. CTL: control phase; First Acute: first acute phase; First PLT: first plateau phase; Final PLT: final plateau phase.

other hand, in the first acute phase, HF in the bradycardic group increased compared with the control value, but $\mathrm{HF}$ in the tachycardic group did not change throughout the experiment. In the final plateau phase, LF in the bradycardic group decreased compared with the control value.

In the first acute and first plateau phases, the $\mathrm{LF} / \mathrm{HF}$ ratio in the tachycardic group showed high values but, due to a small number of tachycardic dogs, 

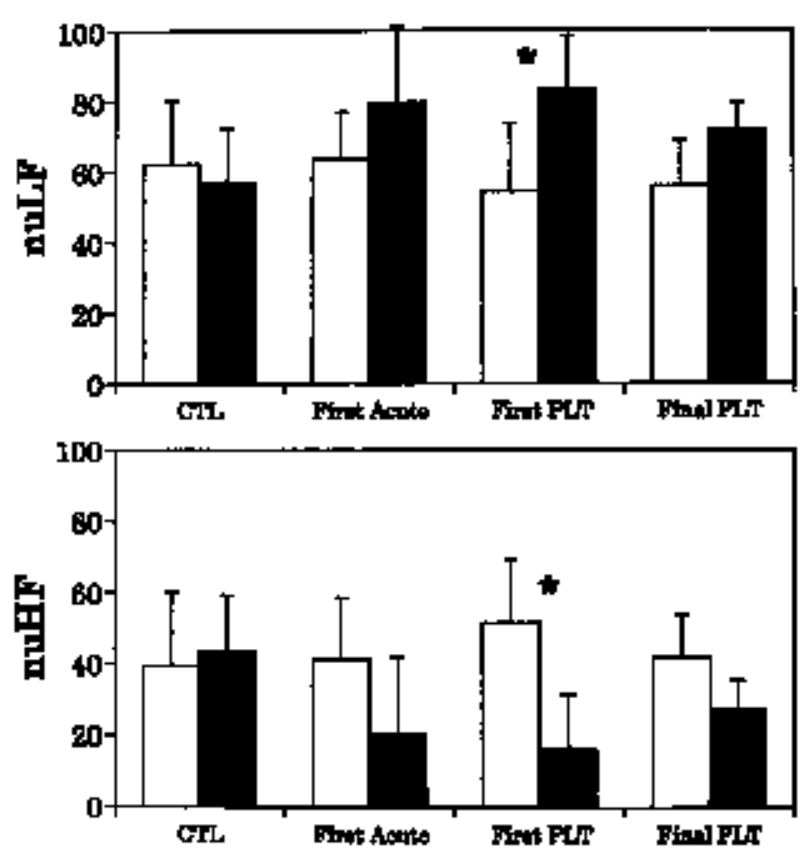

FIGURE 4 Changes in normalized heart rate variability values during massive hemorrhage and progressive hemorrhagic shock. *: $P<0.05$ vs tachycardic group. CTL: control phase; First Acute: first acute phase; First PLT: first plateau phase; Final PLT: final plateau phase.

we could find no statistical significance compared with control. However, in the first plateau phase, LF/HF ratio in the tachycardic group was higher than in the bradycardic group.

Throughout the experiment, nuLF and nuHF in both groups did not change compared with the control values, but in the first plateau phase, we found a difference in nuLF and nuHF values between groups.

\section{Hemodynamic changes (Table)}

Concomitant with progressing hemorrhage, $\mathrm{CO}$ and $\mathrm{S} \overline{\mathrm{V}} \mathrm{O}_{2}$ values showed a marked decrease, but again due to the small number in the tachycardic group the change in $\mathrm{S}_{\bar{v}} \mathrm{O}_{2}$ was not statistically significant.

\section{Metabolic changes (Table)}

After the first plateau phase, arterial $\mathrm{pH}, \mathrm{HCO}_{3}^{-}$and $\mathrm{BE}$ in both groups decreased. In the final plateau phase, $\mathrm{pH}, \mathrm{HCO}_{3}^{-}, \mathrm{BE}$ and lactate in the tachycardic group showed worse values than in the bradycardic group, but again the difference was not statistically significant.
Discussion

Our present experiment involving acute massive hemorrhage demonstrated two types of HR and MAP responses in anesthetized, mechanically ventilated dogs (Figure 1). After massive bleeding caused a MAP of $50 \mathrm{mmHg}$, transient tachycardia was observed in both groups, but the subsequent changes in HR differed markedly in both groups. We could not clarify whether the bradycardic group had better hemodynamic and metabolic consequences than the tachycardic group, because of the small number of dogs in the tachycardic group, but the bradycardic group showed better values.

The results on the relationship between HR and HRV profiles are worth noting. In the bradycardic group, both LF and HF increased in the first acute phase. Gonzalez et al. examined the HRV in three frequency-band areas in conscious rats. ${ }^{21}$ In their experiment, hemorrhage of $30 \%$ blood volume elicited hypotensive bradycardia and the increases in the three frequency-bands observed in our bradycardic group, but Gonzales et al. did not mention hemorrhagic tachycardia. On the other hand, in our tachycardic group, LF increased in the first plateau phase, suggesting the autonomic shift towards sympathetic predominance reported by Madwed et al. ${ }^{23}$ This group found in experiments on conscious dogs that after 30 $\mathrm{ml} \cdot \mathrm{kg}^{-1}$ hemorrhage, low-frequency oscillations in HR (around $0.05 \mathrm{~Hz}$ ) increased and were still present after vagal blockade, suggesting that the cardiac sympathetic nerves may primarily mediate hemorrhageinduced low frequency oscillations in HR.

In order to evaluate the shift in autonomic balance between sympathetic nervous activity and parasympathetic nervous activity, an analysis of LF/HF ratio and normalized unit powers has been recommended. ${ }^{14-18}$ Within both groups these variables did not change compared with the control values. However we found a difference in these values between the bradycardic and tachycardic groups in the first plateau phase, suggesting that the bradycardic group was more inclined towards parasympathetic nervous activity than the tachycardic group.

The present data must be carefully evaluated in terms of data sampling and anesthesia. Spectral analysis needs steady state data. Generally, it is difficult to obtain such a long steady state period during hemorrhage, but we solved this problem by dividing a 608 sec long segment into 16 short sub-segments and averaging them. In reality, as the HR and MAP in the bradycardic group gradually increased from the first acute phase to the first plateau phase (Figure 1), it was difficult to assume that the same sympatho-parasympa- 
TABLE Changes in hemodynamic and metabolic variables during massive hemorrhage and progressive hemorrhagic shock.

\begin{tabular}{|c|c|c|c|c|}
\hline Hemodynamic variables & CTL & First Acute & First PLT & Final PLT \\
\hline \multicolumn{5}{|l|}{$\mathrm{PA}(\mathrm{mmHg})$} \\
\hline Bradycardia & $15.4 \pm 3.4$ & $10.5 \pm 4.1$ & $14.0 \pm 4.2$ & $11.1 \pm 7.6$ \\
\hline Tachycardia & $13.7 \pm 4.9$ & $12.0 \pm 6.6$ & $11.3 \pm 4.6$ & $8.5 \pm 2.1$ \\
\hline \multicolumn{5}{|l|}{ PCWP $(\mathrm{mmHg})$} \\
\hline Bradycardia & $9.6 \pm 3.2$ & $7.5 \pm 4.4$ & $7.7 \pm 5.2$ & $6.0 \pm 4.0$ \\
\hline Tachycardia & $4.3 \pm 3.1$ & $3.0 \pm 3.0$ & $3.5 \pm 5.0$ & $4.0 \pm 2.8$ \\
\hline \multicolumn{5}{|l|}{$\mathrm{CVP}(\mathrm{mmHg})$} \\
\hline Bradycardia & $1.4 \pm 0.3$ & $0.7 \pm 0.3^{\mathrm{a}}$ & $0.9 \pm 0.4^{\mathrm{a}}$ & $0.6 \pm 0.07^{\mathrm{a}}$ \\
\hline Tachycardia & $2.0 \pm 1.0$ & $2.0 \pm 2.1$ & $2.0 \pm 2.6$ & $0.9 \pm 2.7$ \\
\hline \multicolumn{5}{|l|}{$\mathrm{CO}\left(\mathrm{L} \cdot \mathrm{min}^{-1}\right)$} \\
\hline Bradycardia & $1.40 \pm 0.33$ & $0.70 \pm 0.27^{\mathrm{a}}$ & $0.90 \pm 0.43^{\mathrm{a}}$ & $0.58 \pm 0.07^{\mathrm{a}}$ \\
\hline Tachycardia & $1.56 \pm 0.44$ & $0.78 \pm 0.35^{a}$ & $0.75 \pm 0.21^{\mathrm{a}}$ & $0.41 \pm 0.08^{a}$ \\
\hline \multicolumn{5}{|l|}{$\mathrm{S} \overline{\mathrm{v}} \mathrm{O}_{2}(\%)$} \\
\hline Bradycardia & $66 \pm 10$ & $26 \pm 5.6^{\mathrm{a}}$ & $28 \pm 12^{\mathrm{a}}$ & $22 \pm 9.7^{\mathrm{a}}$ \\
\hline Tachycardia & $52 \pm 21$ & $36 \pm 19$ & $30 \pm 15$ & $17 \pm 1.2$ \\
\hline \multicolumn{5}{|l|}{ Metabolic variables } \\
\hline & $C T L$ & First Acute & First PLT & Final PLT \\
\hline \multicolumn{5}{|l|}{$\overline{\mathrm{Hb}\left(\mathrm{g} \cdot \mathrm{dL}^{-1}\right)}$} \\
\hline Bradycardia & $15.0 \pm 3.0$ & $13.6 \pm 2.1$ & $13.1 \pm 2.7$ & $12.5 \pm 2.5$ \\
\hline $\begin{array}{l}\text { Tachycardia } \\
\mathrm{pH}\end{array}$ & $13.4 \pm 5.5$ & $11.8 \pm 4.1$ & $10.8 \pm 2.6$ & $11.1 \pm 2.5$ \\
\hline Bradycardia & $7.36 \pm 0.07$ & $7.39 \pm 0.1$ & $7.25 \pm 0.08^{\mathrm{a} b}$ & $7.16 \pm 0.10^{\mathrm{ab}}$ \\
\hline Tachycardia & $7.29 \pm 0.10$ & $7.31 \pm 0.09$ & $7.18 \pm 0.09$ & $7.07 \pm 0.01^{\mathrm{ab}}$ \\
\hline \multicolumn{5}{|l|}{$\mathrm{Hco}_{3}^{-}\left(\mathrm{mmoL} \cdot \mathrm{L}^{-1}\right)$} \\
\hline Bradycardia & $17 \pm 2.5$ & $15 \pm 2.3$ & $13 \pm 3.0^{\mathrm{a}}$ & $12 \pm 3.0^{\mathrm{ab}}$ \\
\hline Tachycardia & $18 \pm 1.4$ & $16 \pm 1.8$ & $12 \pm 3.0^{\mathrm{ab}}$ & $7.5 \pm 2.1^{\mathrm{abc}}$ \\
\hline \multicolumn{5}{|l|}{$\mathrm{BE}\left(\mathrm{mmoL} \cdot \mathrm{L}^{-1}\right)$} \\
\hline Bradycardia & $-7.1 \pm 3.0$ & $-8.3 \pm 3.0$ & $-13 \pm 3.5^{\mathrm{ab}}$ & $-16.3 \pm 4.3^{\mathrm{a} b}$ \\
\hline Tachycardia & $-8.2 \pm 2.9$ & $-9.7 \pm 3.0$ & $-15 \pm 3.6^{\mathrm{ab}}$ & $-21.8 \pm 2.8^{\mathrm{abc}}$ \\
\hline \multicolumn{5}{|l|}{ Lactate $\left(\mathrm{mmoL} \cdot \mathrm{L}^{-1}\right)$} \\
\hline Bradycardia & $2.5 \pm 1.8$ & $5.3 \pm 5.6$ & $8.0 \pm 8.9$ & $14.3 \pm 13$ \\
\hline Tachycardia & $7.2 \pm 7.6$ & $8.6 \pm 9.6$ & $15.9 \pm 16$ & $18.9 \pm 13$ \\
\hline
\end{tabular}

Values are expressed as mean \pm SD. CTL, control; First Acute, first acute phase; First PLT, first plateau phase; Final PLT, final plateau phase.

${ }^{\mathrm{a}}: P<0.05$ vs $\mathrm{CTL} ;{ }^{\mathrm{b}}: P<0.05$ vs First Acute; ${ }^{\mathrm{c}}: P<0.05$ vs First PLT.

There are no significant differences in the hemodynamic and metabolic variables between the bradycardic group and the tachycardic group.

thetic balance continued during the 608 -sec segment.

The neural regulation of circulatory function is mainly affected by the interplay of sympathetic and parasympathetic outflow, so that activation of either side is accompanied by inhibition of the other. ${ }^{3}$ Therefore, we speculated that in the bradycardic group the transitional alteration from parasympathetic to sympathetic dominance in the autonomic balance must have been present after the massive bleeding, and our method detected it (Figure 3). Concerning the control conditions in both groups, HR exceeded 150 beats. $\mathrm{min}^{-1}$ and MAP exceeded $100 \mathrm{mmHg}$. The present experimental dogs were subjected to alphachloralose anesthesia and mechanical ventilation, and underwent splenectomy. The control values might have been different from conscious and spontaneous breathing state to the experimental state and, in addition, slight hypovolemia associated with splenectomy might have caused sympathetic dominance. However, little is known about HRV alteration due to alphachloralose anesthesia and mechanical ventilation, but we consider that the control HRV values were autonomically well-balanced (Figure 3).

After massive hemorrhage, recovery of MAP in the bradycardic group continued slowly from the first acute phase to the first plateau phase, whereas the MAP in the tachycardic group recovered in a very short time and soon plateaued at a relatively low level. 
In the bradycardic group, parasympathetic nervous activity might have been activated first to prevent cardiac collapse ${ }^{1-6}$ and then sympathetic nervous activity might have been activated gradually, keeping the autonomic balance thereafter. Whereas, in the tachycardic group very soon after massive hemorrhage, sympathetic nervous activity might have been activated. However, in the first plateau phase, HRV values in the bradycardic group returned to the control value, while in the tachycardic group over-excitatory sympathetic nervous activity still continued (Figure 3 ). Thus, in the first plateau phase, the bradycardic group obtained sympatho-parasympathetic nervous homeostasis, but the tachycardic group did not. The difference appeared to depend on the activation of the parasympathetic nervous system.

It seems contradictory that in the first plateau phase although HRV values in the bradycardic group returned to the control value, the HR increased compared with the control value. When the stimulation of unmyelinated vagal cardiac afferents is maintained, their lowering effect on HR and MAP escapes, ${ }^{6,25,26}$ which could explain why the HR and MAP in the bradycardic group increased in the first plateau phase despite the decrease in LF.

In our experiment of progressive hemorrhagic shock, an increase in HR and suppression of both LF and HF in the HRV profile were demonstrated in the bradycardic dogs, while a similar HR increase with suppression of LF and HF as demonstrated in the tachycardic dogs (Figures 2-4). But in the tachycardic dogs, the latter change was statistically insignificant. These data suggest that, as hemorrhagic shock becomes more severe, both sympathetic and parasympathetic nervous activities are finally suppressed, and these changes in autonomic balance might cause the HR increase.

In this study, hemodynamic and metabolic variables and the amount of hemorrhage between groups were not different. But, as we have previously speculated, the small number in the tachycardic group might have prevented statitical significance. Jacobsen et al. ${ }^{27}$ examined the HR difference between bradycardic patients with a mean blood loss of $34 \%$ of estimated blood volume and tachycardic patients with a mean blood loss of $89 \%$ of estimated blood volume. Their results suggest that reversible hypovolemic shock is associated with bradycardia and that hypovolemic shock with tachycardia may represent a transition to an irreversible stage. Thus, during the course of massive hemorrhage, HR changes from initial tachycardia to reversible bradycardia, before finally becoming irreversible tachycardia. Therefore, we should have exam- ined further whether our tachycardic group results mimic the irreversible tachycardia in human studies. Our experimental style of hemorrhage produced far fewer tachycardic than bradycardic dogs, so we finished this experiment at $12 \mathrm{dogs}$, and speculated that the tachycardic group might have a worse outcome than the bradycardic group. However, further studies are needed to clarify this issue.

The progressive hemorrhage markedly aggravated hemodynamic and metabolic variables. As hemorrhagic shock became more severe, hemodynamic and metabolic variables worsened in a stepwise manner, suggesting that these variables can be utilized as indices of the degrees of hemorrhagic shock. However, the HRV profile can graphically demonstrate dynamically changing characteristics of autonomic nervous activity during massive hemorrhage and progressive hemorrhagic shock, and can be utilized as a diagnostic measure of the degrees of hemorrhagic shock.

In conclusion, massive hemorrhage to MAP of $\mathbf{5 0}$ $\mathrm{mmHg}$ caused two types of response in dogs: bradycardia followed by tachycardia, and continuous tachycardia. The HRV profile during massive hemorrhage showed parasympathetic predominance followed by sympathetic-parasympathetic balance in the bradycardic dogs, whereas it showed continuous sympathetic predominance in the tachycardic dogs. However, in progressive hemorrhagic shock of $27 \pm 8 \mathrm{ml} \cdot \mathrm{kg}^{-1}$ body weight, when the MAP did not recover above $50 \mathrm{mmHg}$, the HR increased further, and sympathetic-parasympathetic nervous activities were suppressed in both groups. As a result, we consider the HRV profile to be one good way to assess degrees of hemorrhagic shock.

\section{References}

1 Barcroft H, Edholm OG, McMichael J, Sharpey-Schafer

$E P$. Posthaemorrhagic fainting, study by cardiac output and forearm flow. Lancet 1944; 15: 489-91.

2 Sander-Jensen K, Secher NH, Bie P, Warberg J, Schwartz $T W$. Vagal slowing of the heart during haemorrhage: observations from 20 consecutive hypotensive patients. BMJ 1986; 292: 364-6.

3 Sander-Jensen K, Mehlsen J, Stadeager C, et al. Increase in vagal activity during hypotensive lower-body negative pressure in humans. Am J Physiol 1988; 255: Rl49-56.

4 Converse RL Jr, Jacobsen TN, Jost CMT, et al. Paradoxical withdrawal of reflex vasoconstriction as a cause of hemodialysis-induced hypotension. J Clin Invest 1992; 90: 1657-65.

5 Hayashi T, Shibamoto T, Yamaguchi $\Upsilon$, Wang $H-G$, Tanaka $S$. Suppression of sympathetic nervous system 
is involved in hypotension and bradycardia during hemofiltration in anesthetized dogs. Can J Physiol Pharmacol 1995; 73: 1495-501.

6 Secher NH, Jacobsen J, Friedman DB, Matzen S. Bradycardia during reversible hypovolaemic shock: associated neural reflex mechanisms and clinical implications. Clin Exp Pharmacol Physiol 1992; 19: 733-43.

7 Chen HI, Stinnett HO, Peterson DF, Bishop VS. Enhancement of vagal restraint on systemic blood pressure during hemorrhage. Am J Physiol 1978; 234: H192-8.

8 Öberg B, White $S$. The role of vagal cardiac nerves and arterial baroreceptors in the circulatory adjustments to hemorrhage in the cat. Acta Physiol Scand 1970; 80: 395-403.

9 Koyama S, Aibiki M, Kanai K, Fujita T, Miyakawa K Role of central nervous system in renal nerve activity during prolonged hemorrhagic shock in dogs. Am J Physiol 1988; 254: R761-9.

10 Koyama S, Sawano F, Matsuda $\Upsilon$, et al. Spatial and temporal differing control of sympathetic activities during hemorrhage. Am J Physiol 1992; 262: R579-85.

11 Morita H, Vatner SF. Effects of hemorrhage on renal nerve activity in conscious dogs. Circ Res 1985; 57 : 788-93.

12 Skoog P, Månsson J, Thorén P. Changes in renal sympathetic outflow during hypotensive haemorrhage in rats. Acta Physiol Scand 1985; 125: 655-60.

13 Levy MN. Sympathetic-parasympathetic interactions in the heart. Circ Res 1971; 29: 437-45.

14 Rimoldi 0, Pierini S, Ferrari A, Cerutti S, Pagani M, Malliani A. Analysis of short-term oscillations of R-R and arterial pressure in conscious dogs. Am J Physiol 1990; 258: H967-76.

15 Akselrod S, Gordon D, Madwed JB, Snidman NC, Shannon DC, Cohen RJ. Hemodynamic regulation: investigation by spectral analysis. Am J Physiol 1985; 249: H867-75.

16 Malliani A, Pagani M, Lombardi F, Cerutti S. Cardiovascular neural regulation explored in the frequency domain. Circulation 1991; 84: 482-9.

17 Hughson RL, Maillet A, Gauquelin G, Arbeille P, ramamoto $\Upsilon$, Gharib $C$ Investigation of hormonal effects during 10-h head-down tilt on heart rate and blood pressure variability. J Appl Physiol 1995; 78: 583-96.

18 Pagani M, Lombardi F, Guzzetti S, et al. Power spectral analysis of heart rate and arterial pressure variabilities as a marker of sympatho-vagal interaction in man and conscious dog. Circ Res 1986; 59: 178-93.

19 Komatsu T, Singh PK, Kimura T, Nishiwaki K, Bando $K$, Shimada $\Upsilon$ Differential effects of ketamine and midazolam on heart rate variability. Can J Anaesth 1995; 42: 1003-9.
20 Kawase M, Komatsu T, Kondo U, Nishiwaki K, Kimura T, Shimada $\Upsilon$ Hemorrhage exerts different effects on variabilities of heart rate and blood pressure in dogs. (Japanese) Masui 1998; 47: 925-32.

21 Gonzalez JG, Valeriano JJC, Rodriguez MF. Autonomic mediation of short-term cardiovascular oscillations after acute hemorrhage in conscious rats. J Auton Nerv Syst 1995; 55: 123-30.

22 Madwed JB, Cohen RJ. Heart rate response to hemorrhage-induced $0.05-\mathrm{Hz}$ oscillations in arterial pressure in conscious dogs. Am J Physiol 1991; 260: H1248-53.

23 Cox $R H$. Influence of chloralose anesthesia on cardiovascular function in trained dogs. Am J Physiol 1972; 223: 660-7.

24 Carneiro JJ, Donald DE. Blood reservoir function of dog spleen, liver, and intestine. Am J Physiol 1977; 232: H67-72.

25 Abrahamsson H, Thorén P. Reflex relaxation of the stomach elicited from receptors located in the heart. An analysis of the receptors and afferents involved. Acta Physiol Scand 1972; 84: 197-207.

26 Abrahamsson H, Thorén P. Vomiting and reflex vagal relaxation of the stomach elicited from heart receptors in the cat. Acta Physiol Scand 1973; 88: 433-9.

27 Jacobsen J, Secher NH. Heart rate during haemorrhagic shock. Clin Physiol 1992; 12: 659-66. 